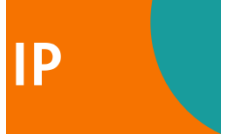

\title{
Non-fatal burn is a major cause of illness: findings from the largest community-based national survey in Bangladesh
}

S R Mashreky, A Rahman, S M Chowdhury, et al.

Inj Prev 2009 15: 397-402

doi: 10.1136/ip.2009.022343

Updated information and services can be found at:

http://injuryprevention.bmj.com/content/15/6/397.full.html

These include:

References This article cites 17 articles, 1 of which can be accessed free at: http://injuryprevention.bmj.com/content/15/6/397.full.html\#ref-list-1

Email alerting Receive free email alerts when new articles cite this article. Sign up in the service box at the top right corner of the online article.

Notes

To order reprints of this article go to:

http://injuryprevention.bmj.com/cgi/reprintform

To subscribe to Injury Prevention go to:

http://injuryprevention.bmj.com/subscriptions 


\title{
Non-fatal burn is a major cause of illness: findings from the largest community-based national survey in Bangladesh
}

\author{
S R Mashreky, ${ }^{1,2}$ A Rahman, ${ }^{1}$ S M Chowdhury, ${ }^{1}$ T F Khan, ${ }^{3}$ L Svanström, ${ }^{2}$ F Rahman ${ }^{1,2}$
}

${ }^{1}$ Centre for Injury Prevention and Research Bangladesh (CIPRB), Bangladesh; ${ }^{2}$ Department of Public Health Science, Karolinska Institutet, Sweden; ${ }^{3}$ Centre for Medical Education, Bangladesh

Correspondence to:

Dr S R Mashreky, Centre for Injury Prevention and Research Bangladesh (CIPRB),

Bangladesh;

mashreky@ciprb.org

Accepted 12 August 2009

\section{ABSTRACT}

Objective: To examine the incidence and characteristics of non-fatal burn injury in Bangladesh.

Methods: A population-based cross-sectional survey was conducted between January and December 2003 in Bangladesh. Nationally representative data were collected from 171366 rural and urban households, with a total sample size of 819429 .

Results: The incidence of non-fatal burns was 166.3 per 100000 per year. The rate was higher in females than in males (RR 1.15; 95\% Cl 1.03 to 1.27). Children less than 5 years of age were at much higher risk of burn injury than those older than 5 years (RR 7.05; 95\% Cl 6.35 to 7.8). Rural people were at more than three times higher risk of burn. The average number of days absent from school due to burn injury was 21.64 (SD 19.64); the average number of workdays lost was 22.96 (SD 35.94). The average duration of assistance required in daily living activities was 17.26 (SD 20.34) days. The hospitalisation rate was 12.6 per 100000 population per year. The mean duration of hospital stay was 15.88 (SD 20.47) days. The rate of permanent disability was 2.6 per 100000 populationyears.

Conclusion: Burn is a major cause of morbidity, disability, school absence, and workday loss. Young children, females, and rural dwellers are at highest risk. Home is the most risky place for children and females in terms of burn injury risk. To halt this devastating health issue, a national strategy and programme for burn prevention must be developed.

In terms of morbidity and long-term disability, burn is a huge public health problem throughout the world and especially in developing countries. ${ }^{1}$ Burn is a more complicated health problem in low income countries (LIC) because management requires specialised personnel and technologies that can be expensive and not always readily available. $^{2}$ Acute burn care is a costly service. ${ }^{3-7}$ The non-financial consequences of burn injury are also large and potentially devastating, thus efforts in prevention are more urgent than reflected in mortality statistics. ${ }^{8}$

Statistics available in Bangladesh underestimate the true incidence of burn injury due to the country's poor record-keeping system. This has obscured the status of burn as a major public health issue. It is not surprising then that a lack of concerted effort has been focused on prevention. While the epidemiology of childhood burn was explored in Bangladesh, ${ }^{10}$ the overall magnitude of burn injuries has not been documented. This population-based survey provided evidence on the epidemiology of non-fatal burn injury among the urban and rural population in Bangladesh, and provided the basis for a burn prevention programme in the country.

\section{METHODS}

\section{Study design}

This was a cross-sectional study.

\section{Study population}

The study was carried out during 2003 (January to December) in 12 randomly selected districts of Bangladesh and in Dhaka Metropolitan City. This encompassed a total population of 819429.

Multi-stage cluster sampling was used to choose a total sample size of 171366 households: 88380 from rural areas, 45183 from district towns (urban areas), and 37803 from Dhaka Metropolitan City.

Bangladesh has a total of 64 districts. Twelve of these were chosen by simple random sampling. Each district comprises several upazilas (subdistricts). One upazila was randomly selected from each selected district. An upazila comprises a number of unions. A union is the lowest administrative unit comprising $\sim 20000$ population. From each upazila two unions were selected randomly and each union was considered a cluster. All households in the union were included in the survey. The district headquarters of the 12 selected districts and Dhaka Metropolitan City constituted the urban areas. In the urban areas, mohallas served as clusters. Mohallas are the lowest unit of the city corporation. About 400-500 households constitute a mohalla. Systematic sampling was done to achieve the required number of households.

\section{Case ascertainment}

Anyone who was burned and received treatment or could not perform normal activities for at least 3 days was included as a case of burn injury.

\section{Data collection and interview}

Forty-eight data collectors (all full-time employees) collected data from respondents through face-toface interviews. Along with the researchers, six full-time supervisors were employed for the supervision and monitoring of the data collection process. Both the supervisors and data collectors were trained in the data collection process. Mothers were preferred as respondents. However, if the mother was not available the most knowledgeable members of the household were considered 
as respondents. Where possible, the head of household and as many members of the household as possible were present to corroborate or add detail to the respondent's interview answers. Screening forms were used to identify any mortality or morbidity in the household. A household member was defined as someone living in the same house, including domestic helpers or long-term guests who shared meals and participated in the daily activities within the household.

The respondents were first asked whether there had been any illness or injury at home in the last 6 months. If any illnesses/ injuries were identified, the interviewer proceeded with further clarification regarding the injuries. Structured questionnaires were employed if burn injuries caused the illness. Repeat visits were made to the households where respondents were unavailable during the first visit. In spite of repeated attempts, $2.7 \%$ of households could not be interviewed. A total of 166766 households completed participation in the study.

\section{Definition of severity}

Non-fatal burns were separated into degrees of severity. These were:

- Severe: permanently disabled (loss of vision, hearing, handling, ambulation, or mental retardation), regardless of whether hospitalisation occurred or not.

- Serious: hospitalised for 10 days or more, but no permanent disability.

- Major: hospitalised, for a period of less than 10 days but no permanent disability.

- Moderate: sought medical care, but not admitted to hospital; or a 3-day work loss, or absence from school, but suffered no permanent disability. Three days devoid of normal daily routine was set as the minimum number of days to define "moderate severity". This was determined following discussion with social scientists and epidemiologists familiar with Bangladeshi cultural norms.

- Permanent disability was defined as any of the part of the body losing function permanently.

\section{Definition of cost of treatment}

Treatment cost referred to out-of-pocket expenditures made by the family. The cost of the service by a government hospital was not included in this cost calculation.

\section{Statistical analysis}

Standard descriptive statistics were used to analyse the characteristics of burn patients and their injuries. Mean, SD, and proportion were used where appropriate. Burn injuries were presented by gender, age, and place of residence. Age was categorised in seven groups. The yearly incidence of burn was calculated from the occurrence of burn morbidity in 6 months multiplied by 2 , as data were collected with a 6-month recall period. Rates were calculated with 95\% CIs. Relative risk (RR) was calculated to compare the burn risk in different age groups, place of residence, and gender by using a $2 \times 2$ table in EPIinfo software.

\section{RESULTS}

A total of 1363 non-fatal unintentional burn cases were found in this study. Among the burned, 648 (47.6\%) were male and $715(52.4 \%)$ were female. The mean age of burn victims was 12.2 (SD 14.5) years, ranging from 0 to 77 years. The majority of burn victims were very poor. About $86 \%$ of burn victims' families earned less than $\$ 100$ a month, and over $50 \%$ earned less than $\$ 50$ a month.

Age was a determinant of burn injury risk. Risk was higher among the younger age groups. Children aged $0-4$ years were the most vulnerable group, with a risk 7 times higher than those older than 5 years (RR 7.05; 95\% CI 6.35 to 7.8). The older the age group, the lower the burn risk. Rural populations were at higher risk ( $\mathrm{RR} 3.23$; 95\% CI 5.36 to 54.64 ) of burn injury compared to urban populations. In comparison to males, females were at higher risk (RR 1.15; 95\% CI 1.03 to 1.27 ) of burn.

The rate of non-fatal burn in Bangladesh was 166.3 per 100000 population per year. Rates were 177.6 and 155.2 per 100000 population year among females and males, respectively. The highest rate (680.6 per 100000 population per year) of nonfatal burns was found in children aged $0-4$ years. Contrary to the overall trend, in this youngest age group boys suffered from a significantly higher rate of burn (784.8; 95\% CI 706.3 to 869.5).

Open flames and hot liquids were each responsible for about $36 \%$ of burn injuries in all age groups. Hot objects were responsible for about $24 \%$ of the total non-fatal burn incidences. About $2 \%$ of burns were caused by chemicals, and less than $1 \%$ were caused by explosives.

Scalding from hot liquids was the major cause of burn among females aged 15-44 years; flame was the major cause of burn among 0-14-year-old boys.

Approximately $55 \%$ of flame burns were caused by cooking fires, $12.8 \%$ by fires used for heating, and $7 \%$ by kerosene lamps; the remaining cases were caused by electrical sparks producing fire, house fires, and fires in the workplace.

Hot water was the most common cause $(25 \%)$ of scalding. Liquid food and hot rice water caused $21.5 \%$ and $22.2 \%$ of scalding, respectively. Cooking oil caused about $14 \%$ of scalding cases. More than $92 \%$ of scalding cases occurred at home; of them, approximately $77 \%$ occurred in the kitchen.

Hot coal, cooking utensils, hot machinery parts, and hot clothes-irons were found to be the most common cause of contact burn in this study. Only $2.6 \%$ of non-fatal burns were chemical burns. Among them more than $80 \%$ were caused by acid and the rest by lime and other chemicals.

The majority (86.7\%) of non-fatal burns took place during the day, between the hours of 06:00 and 18:00. About 64\% of nonfatal burns occurred between $06: 00$ and 15:00. Only 1.2\% of non-fatal burns took place between midnight and early morning.

Table 1 Risk factors of burn injury

\begin{tabular}{lllll}
\hline & & $\begin{array}{l}\text { Rate per } \\
\mathbf{1 0 0} \mathbf{~ 0 0 0} \\
\text { population/year }\end{array}$ & RR (95\% CI) & p Value \\
\hline $\begin{array}{l}\text { Sex } \\
\quad \text { Male }\end{array}$ & 648 & 155.2 & 1 & \\
$\quad$ Female & 715 & 178.6 & $1.15(1.03$ to 1.27$)$ & 0.01 \\
Age & & & & \\
$\quad<5$ years & 615 & 680.6 & $7.05(6.35$ to 7.8$)$ & 0.000 \\
$\quad \geqslant 5$ years & 749 & 102.7 & & \\
$\begin{array}{l}\text { Place of residence } \\
\quad \text { Urban }\end{array}$ & 293 & 76.7 & 1 & \\
$\quad$ Rural & 1070 & 246.2 & $3.23(2.84$ to 3.69) & 0.000 \\
\hline
\end{tabular}


Figure 1 Incidence of non-fatal burn by age and sex.

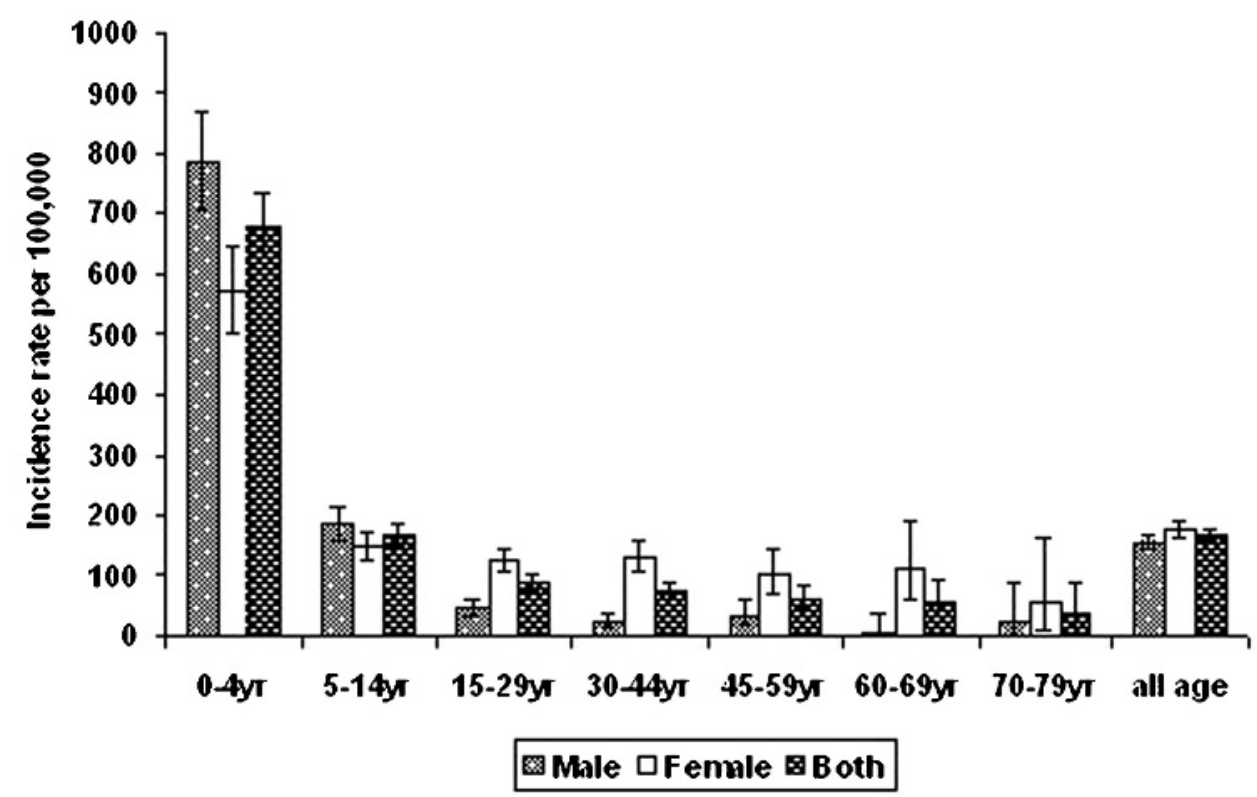

\section{Place of injury}

The majority (89\%) of non-fatal burns took place at home. The kitchen was the most common place of burn injury where more than $50 \%$ of the non-fatal burn cases had occurred. The courtyard (21\%) was the second most common place of non-fatal burns at home. More than $93 \%$ of burn injuries among children less than 5 years old took place at home. Over $31 \%$ of males older than 5 years were burned beyond the confines of their home. Among females, only $5 \%$ receive burns outside the home.

Burns occurred outside the home in highways and streets, factories, the office, shops, hotels, agricultural fields and farms, and other commercial places.

\section{Activities prior to burn injury}

About $25 \%$ of the burn victims were engaged in household chores when burned. About $11 \%$ were playing with fire or some hot object, and more than $7 \%$ were warming-up, sitting close to a source of fire.

\section{Hospitalisation}

Among all non-fatal burns, 103 were admitted to hospital $(7.6 \%$ of non-fatal burn cases). The overall hospitalisation rate due to burn was 12.6 per 100000 population-year. Although the hospitalisation rate was higher among females (13.4 per 100000 population-year) than males (11.8 per 100000 population-year), the difference was not statistically significant. The highest hospitalisation rate (43.2 per 100000 population-year) was found among children less than 5 years old. The lowest hospitalisation rate (3.8 per 100000 population-year) was among the age group of $60+$ years.

Overall, the duration of hospital stay due to burn was 15.88 (SD 20.47) days. Among females the length of stay was significantly longer (21.79 days) than for males (9.4 days). The longest hospital stay (25.41 days) was among the 15-29year-old age group.

\section{Disabilities}

Among non-fatal burn cases, 21 were permanently disabled, giving an overall rate of permanent disability of 2.6 per 100000 population-year. The rates of permanent disability were 5.53 and 7.61 per 100000 population-year among age groups $<5$ years and 5-14 years, respectively.

The average duration of school days lost was 21.64 (SD 19.64) days when burns of all severity were considered. When considering only hospitalised burn cases, the number of school days lost was 50.66 (SD 17.07). For moderate to severe burn cases, the average number of workdays lost was 22.96 (SD 35.94). Hospitalised victims lost 31.95 (SD 32.15) workdays. The majority (68\%) required assistance in their daily activities. The average duration of assistance required was 17.26 (SD 20.34) days for non-hospitalised and 29.58 (SD 32.16) days for hospitalised burn cases.

Table 2 Causes of burn by age

\begin{tabular}{lccccc}
\hline Age group & $\begin{array}{l}\text { Flame } \\
\mathbf{n}(\%)\end{array}$ & $\begin{array}{l}\text { Hot liquid } \\
\mathbf{n}(\%)\end{array}$ & $\begin{array}{l}\text { Hot object } \\
\mathbf{n}(\%)\end{array}$ & $\begin{array}{l}\text { Chemical } \\
\mathbf{n}(\%)\end{array}$ & $\begin{array}{l}\text { Explosive } \\
\mathbf{n}(\%)\end{array}$ \\
\hline 0-4 years & $224(36.4)$ & $185(30.1)$ & $196(31.9)$ & $7(1.1)$ & $3(0.5)$ \\
$5-14$ years & $135(38.2)$ & $120(34.0)$ & $91(25.8)$ & $7(2.0)$ & $0(0.0)$ \\
$15-29$ years & $70(34.8)$ & $97(48.3)$ & $23(11.4)$ & $11(5.5)$ & $0(0.0)$ \\
$30-44$ years & $37(29.4)$ & $70(55.6)$ & $12(9.5)$ & $7(5.6)$ & $0(0.0)$ \\
$45-59$ years & $23(47.9)$ & $14(29.2)$ & $8(16.7)$ & $3(6.3)$ & $0(0.0)$ \\
$60-69$ years & $4(28.6)$ & $8(57.1)$ & $2(14.3)$ & $0(0.0)$ & $0(0.0)$ \\
$70-79$ years & $5(100.0)$ & $0(0.0)$ & $0(0.0)$ & $0(0.0)$ & $0(0.0)$ \\
All ages & $498(36.6)$ & $494(36.3)$ & $332(24.4)$ & $35(2.6)$ & $3(0.2)$ \\
\hline
\end{tabular}


Figure 2 Hospitalisation due to burn by age and sex (rate per 100000 populationyears).

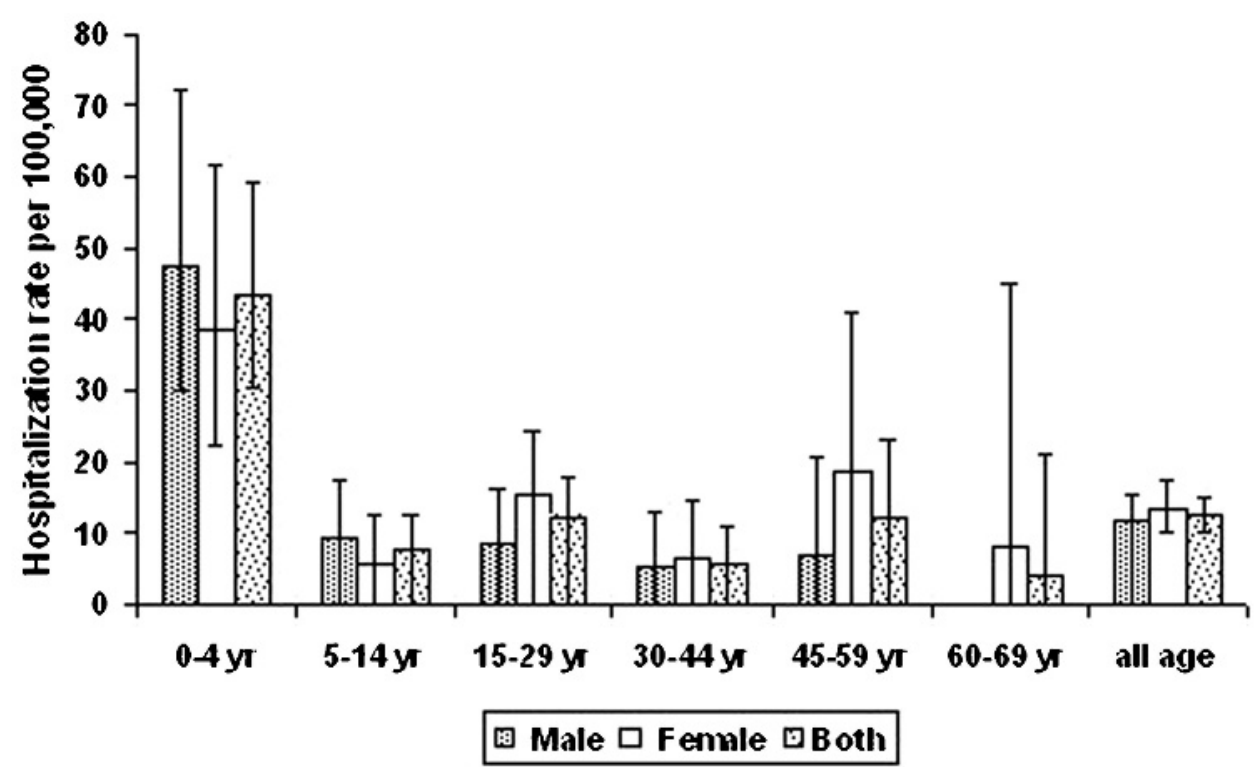

\section{Cost of burn management}

Average out-of-pocket expenses for the care of a burn were about $\$ 22$ per family. The cost increased with the severity of burn. The average cost for serious and major burns was $\$ 166$ and $\$ 58$ per burn injury, respectively. For the treatment of a severe burn, a family spent $\$ 462$.

\section{DISCUSSION}

In Bangladesh, about 233000 people suffer from moderate to severe burns every year; among them approximately 18000 need hospitalisation and more than 3600 people became permanently disabled. Young children were found to be the most vulnerable group, with the risk of burn injury more than 7 times higher than for older groups.

The finding is consistent with many other studies. In Israel, for example, $53 \%$ of burn related hospitalisations were of children aged 0-14 years, and of them, 76\% were younger than 4 years. ${ }^{11}$ In Turkey, half of the hospitalised burn patients were in the age group of $0-14$ years, and those under 4 years old had the highest rate of burn. ${ }^{14}$ Over $50 \%$ of the total number of disability-adjusted life years lost globally due to fire related burns are among children aged $0-14$ years. ${ }^{12}$

In this study we found that females were $15 \%$ more likely (RR 1.15; 95\% CI 1.03 to 1.27 ) to suffer from burn injury. Females aged 10 years and above suffered from a higher rate of occurrence of burn injury because it is usually at this age that they start helping in the kitchen. ${ }^{9}$ In neighbouring countries, such as India and Pakistan, females also make up the majority of burn victims. ${ }^{15} 1718$ Similar results were obtained in Egypt where the use of traditional kerosene stoves for cooking was condemned as a major reason for causing higher rates of burn among females. ${ }^{13}$

This study also found a significantly longer duration of hospital stay for female burn victims in comparison to males. An unsafe kitchen environment, loose clothing, and use of traditional open cookers (chula) and biofuel (wood, leaf, cow dung) mean increased exposure to severe burn. This may be a reason for the higher risk of burn and longer duration of hospital stay for females.
Figure 3 Duration of hospital stay by age and sex.

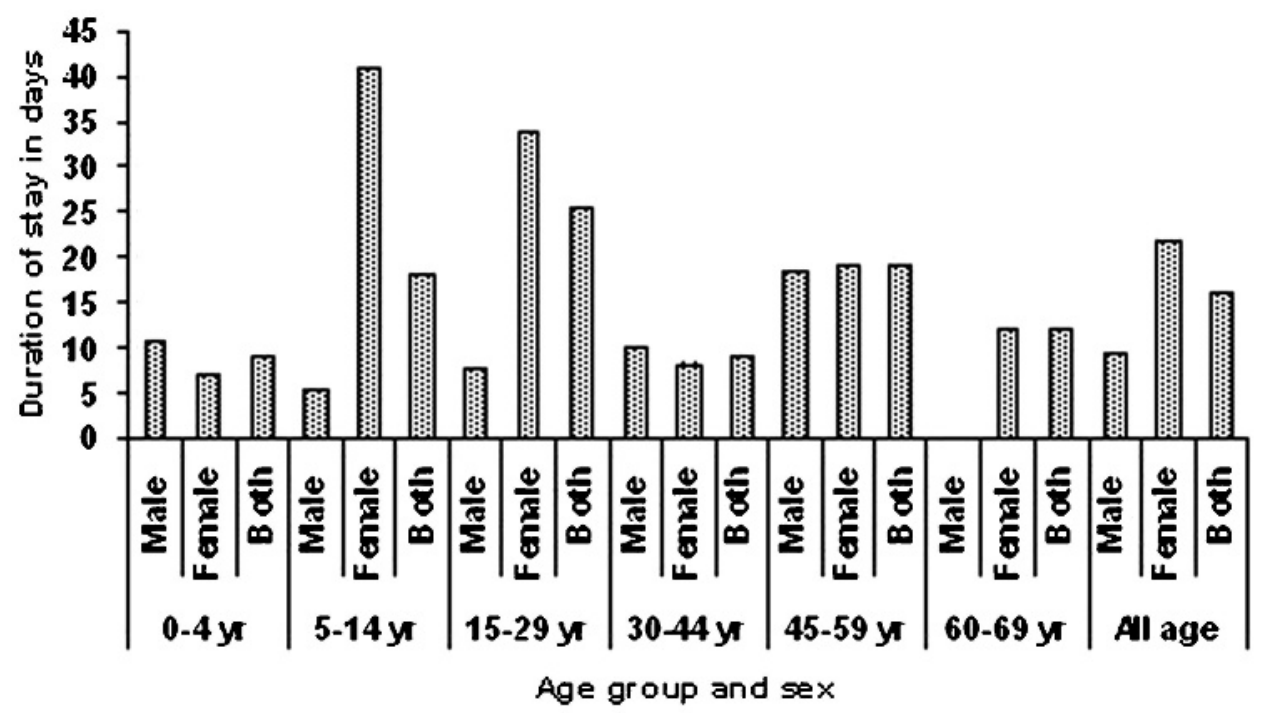


Figure 4 Cost of burn management by severity of injury.

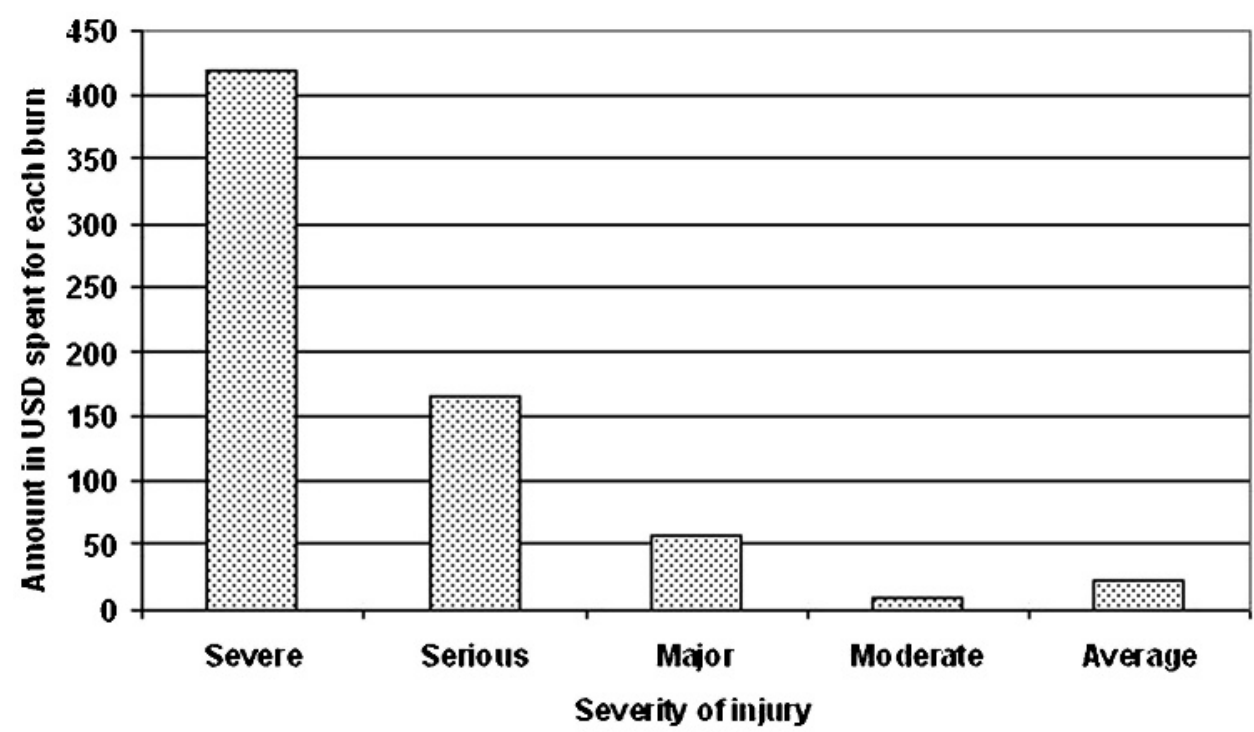

Most burn injuries occurred at home. However, stratification by gender showed that burn injuries among older males ( 5 years and above) happened more commonly outside the home. As shown also in other studies, ${ }^{16}$ males generally work and stay outside the home for longer periods at a time than females, which renders them prone to burn injuries at their workplace or other places outside home.

The risk of burn injuries was more than three times higher among the rural population than the urban population (RR 3.23; 95\% CI 5.36 to 54.64). Rural households and surrounding premises are at risk of fire and burn because of their infrastructure and the activities of household occupants. In rural areas, walls and roofs are made of jute sticks, hay, palm leaves, and bamboo, which are flammable. Stoves are placed at ground level without barrier protection for children. Dry wood, leaves, and cow dung are commonly used fuels, and these flammable bio-fuels are often kept near the stove.

The use of traditional kerosene lamps (kupi bati) is another common cause of burn injury. Kupi bati is a home made lamp, which is unstable and prone to tipping over when alight, causing kerosene to spill and spread flames.

Hot liquid is another major risk factor of scalding in Bangladesh. When cooking rice, the excess water is drained from the boiling rice and kept near the cooking area, which is later used to feed the cattle. This boiled rice-water is very thick. Adults can get scalded while draining this boiling rice-water and children can fall in the container and suffer serious scalding. Storing burning ashes at home is another risk for childhood burn. To clear space in the stove, burning ashes are kept in a pile near the cooking area to cool down. This is later used as scouring powder for cleaning pots and pans. Yet ashes require many hours to cool down completely and during this period children may be burned by stepping or falling into the pile of hot ash.

\section{Limitations and strengths}

This is the largest community-based injury survey in Bangladesh, and findings of this study represent national statistics. As in most other low income countries, a large number of people in Bangladesh do not attend hospitals even if suffering from a severe injury. To compound this, a poor hospital record keeping system does not always record and collate burn injury information correctly. As a result hospital statistics are under-reported. As this is a household survey, findings of this study provide a more accurate picture of injury in Bangladesh. A 6-month recall was used in detecting burn injury. Some moderate injuries may not have been captured because of long recall periods.

\section{Conclusions and recommendations}

Burn is a major cause of morbidity and disability in Bangladesh. Burn is also a major cause of hospitalisation and is responsible for prolonged hospital stays, school absence, and workday loss. The magnitude and consequences of this problem make burn injury an urgent public health problem. A national strategy and programme for burn prevention is crucial. In implementing a prevention programme, special attention needs to be given to age group, sex, and place of residence so that prevention measures can be tailored according to these different factors. Health education and household environmental modification, especially of the kitchen environment, should comprise a major component of the prevention programme.

\section{What is already known on the subject}

The epidemiology of childhood burn in Bangladesh has previously been described.

\section{What this study adds}

A representative sample of burns to persons of all ages was studied.

- More than 233000 people are burned every year in Bangladesh; among them 18000 need hospitalisation and 3600 become permanently disabled.

- Children and females are the most vulnerable group to burn injury.

- Rural people are at significantly higher risk of burn.

- Burn is a major cause of school absence and workday loss. 
Acknowledgements: We are grateful to UNICEF, Bangladesh who funded the study. In particular, we thank Stephanie Ryan of CIPRB, for assistance with translation.

Funding: The study was funded by UNICEF, Bangladesh.

Competing interests: None declared.

Ethics approval: Ethical clearance was obtained from the Ethical Committee of the Institute of Child and Mother Health, Dhaka.

Provenance and peer review: Not commissioned; externally peer reviewed.

\section{REFERENCES}

1. Heimbach D. Burn patients, then and now. Burns 1999;25:1-2.

2. Lari AR, Panjeshahin MR, Talei AR, et al. Epidemiology of childhood burn injuries in Fars Province, Iran. J Burn Care Rehabil 2002;23:39-45.

3. Takayanagi K, Kawai S, Aoki R. Cost of burn care and implication for efficient care. Clin Perform Qual Health Care 1999;7:70-3.

4. Keswani MH. The 1996 Everett Idris Evans Memorial Lecture. The cost of burns and the relevance of prevention. J Burn Care Rehabil 1996;17:485-90.

5. Dimick AR, Potts LH, Charles ED Jr, et al. The cost of burn care and implications for the future on quality of care. J Trauma 1986;26:260-6.

6. Griffiths HR, Thornton KL, Clements CM, et al. The cost of a hot drink scald. Burns 2006;32:372-4.

7. Eldad A, Stern Z, Sover $\mathrm{H}$, et al. The cost of an extensive burn survival. Burns 1993;19:235-8.
8. Rivara FP. Burns: the importance of prevention. Inj Prev 2000;6:243-4.

9. Mashreky SR, Rahman A, Chowdhury SM, et al. Epidemiology of childhood burn: yield of largest community-based injury survey in Bangladesh. Burns 2008;34:856-62.

10. Mashreky SR, Rahman A, Chowdhury SM, et al. Consequences of childhood burn: findings from the largest community-based injury survey in Bangladesh. Burns 2008;34:912-8.

11. Peleg K, Goldman S, Sikron F. Burn prevention programs for children: do they reduce burn-related hospitalizations? Burns 2005;31:347-50.

12. Peden M, McGee K, Sharma G. The injury chart book: a graphical overview of the global burden of injuries. Geneva: World Health Organization, 2002.

13. Hemeda M, Maher A, Mabrouk A. Epidemiology of burns admitted to Ain Shams University Burns Unit, Cairo, Egypt. Burns 2003;29:353-8.

14. Anlatici R, Ozerdem OR, Dalay C, et al. A retrospective analysis of 1083 Turkish patients with serious burns. Burns 2002;28:231-7.

15. Marsh D, Sheikh A, Khalilz A, et al. Epidemiology of adults hospitalized with burns in Karachi, Pakistan. Burns 1996;22:225-9.

16. Forjuoh SN. Burns in low- and middle-income countries: a review of available literature on descriptive epidemiology, risk factors, treatment, and prevention. Burns 2006;32:529-37.

17. Batra AK. Burn mortality: recent trends and socio-cultural determinants in rural India. Burns 2003;29:270-5.

18. Muqim RUI, Zareen M, Dilbag, et al. Epidemiology and outcome of burns at Khyber teaching hospital Peshawar. Pakistan Journal of Medical Science 2007;23:420-4. 